and the values of $a, b$ and $c$ for any given colour be read from the C.I.E. colour chart, the value of $Q$ turns out to be the rod to cone ratio for the colour match. The extent of this agreement is indicated in Fig. 2, where the observed and calculated values for spectral colour matches are plotted together.

Consideration of Fig. 1 might suggest that any combination of rod and cone responses, and therefore any colour sensation, should be obtainable by suitably mixing an extreme violet, stimulating rods only, with an extreme red, stimulating cones only. The effects of raising the light intensities at these wavelengths sufficiently to produce the necessary rod and cone responses have, however, to be considered. It is significant that the purples obtained by mixtures of red and violet can be converted into white by the addition of a suitable green.

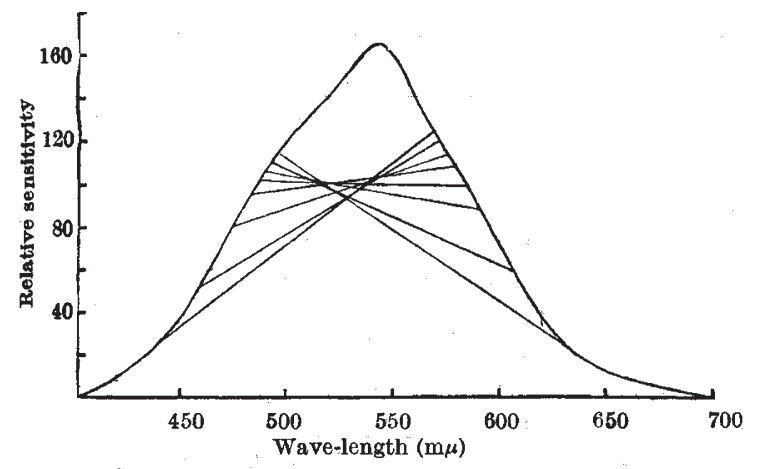

Fig. 3. SUMMAMION OF SCOTOPIO AND PHOTOPIO CURVES ; COM-

PLEMBNTARY WAVE-LENGTHS CONNECTED BY BTRAIGHT LINES.

A particularly interesting, though somewhat mysterious, confirmation of the hypothesis is obtained from a consideration of the effects of summating rod response and cone response. Physiologically, such summation might occur on the bipolar cells or on ganglion cells. The exact position of its occurrence is for the present irrelevant. When the scotopic and photopic visibility curves are summated, the curve shown in Fig. 3 is obtained, and it is clear from a study of this figure that such a curve has all the selient characteristics of the previously entirely empirical colour triangle. The lines joining points on the curve corresponding to complementary pairs all pass through nearly the same point; all wave-lengths shorter than $440 \mathrm{~m} \mu$ or longer than $640 \mathrm{~m} \mu$ are com: plementary to 570 and $496 \mathrm{~m} \mu$ respectively, and greens can only have purples as complementaries. In this diagram the limits of the spectrum turn outwards, whereas in the colour triangle they are generally represented as turning inwards. The interpretation of this whole phenomenon is obscure, but its significance as a confirmation of the essential part played in colour vision by the facts described by the rod and cone sensitivity curves is manifest.

So far it has been tacitly assumed that, owing to the adaptation powers of the retina, rod and cone responses can be represented on the same scale, that is to say, the visibility curves can be directly compared in order to estimate the frequency of impulses travelling up the separate rod and cone fibres. This is the simplest assumption and may be used as a working hypothesis. It means that should, for any reason, the sensitivity of the rods with respect to the cones be increased or decreased, then some form of colour blindness would result. For example, many of the properties of the deuter. anope would receive an explanation if his rods were relatively less sensitive than his cones. Similarly, the protanope would possess rods which were more sensitive than normal relative to the cones. Such quantitative variations in sensitivity of existing units would seem to be a more probable explanation of at least certain types of abnormalities of colour percep. tion than the presence or absence of whole systems of hypothetical sensory units.

These selected points may be sufficient to indicate at least the possibility of interpreting colour phenomena in terms of the known activity of rods and cones. Naturally, there are difficulties, not the least of which is the structure and behaviour of the fovea, but these may perhaps yield to further investigation, and the hypothesis has the merits of not multiplying the sensory elements and of not invoking any struc. tures which are not demonstrable.

${ }^{3}$ Granit, NATURE, 151, 11 (1943).

Studnitz, Z. verg. Physiol., 28, 153 (1940) (Abstract only).

- Hecht, J. Opt. Soc. Amer., 20, 231 (1930).

- Hecht and Williams, J. Gen. Physiol., 5, 1 (1923).

'Ludvigh, Arch. Ophthal., 20, 713 (1938).

- Sloan, Psych. Mon., 38, 1 (1928).

'Ludvigh, Arch. Ophthal., 24, 168 (1940).

" Polyak, "The Retina", Chicago (1941).

${ }^{9}$ Detwiler, J. Opt. Soc. Amer., 30, 42 (1940).

${ }^{10}$ Kravkov, J. Opt. Soc. Amer., 31, 335 (1941).

\section{SCIENTIFIC DISCOVERIES BY ACCIDENT}

\section{BY T. LL. HUMBERSTONE}

$H^{O R T U N A}$ favet fatuis is a familiar Latin tag. $1 \mathrm{Mad}$ or sane, the man of science must thank fortune or acçident for useful discoveries in medicine physics and ehemistry. Pasteur said that chance favours those who are prepared. Accidental dis coveries may have been forfeited owing to complete concentration on the primary object of the research But those recorded are numerous. A few examples will demonstrate their value and variety.

Minkowski and von Mehring investigated the pancreas in relation to digestion. A laboratory attendant noticed that the urine of a dog deprived of its pancreas attracted swarms of flies. This was due to increased sugar content. The link between diabetes and the pancreas was established; the disease had been artificially induced and the way was open to Banting and Best for the discovery of insulin. Sir Lauder Brunton declared that his discevery of the effect of nitrites in dilating the arteries was accidental. For sufferers from that cruel disease angina pectoris, the drug acts like a charm. Diathermy and the induction of artificial fevers, new and important methods of treatment, were due to a feeling of discomfort noticed by one of Willis R. Whitney's assistants in attending to a high-frequency transmitter. Koch discovered how to separate microbes in a mixed culture through a half-potato left on his laboratory bench. By chance, two medical men discovered that mumps may cure whooping cough. 'Prof. Archibald Fleming's recent discovery of the bacillus-devouring power of Penicillium notatum was due to a chance observation.

In physics, chance discoveries have added to the wealth and happiness of mankind. A spectaclemaker of Middleburg who looked at a weathercock 
through two lenses was surprised to see an enlarged and inverted weathercock. The discovery was of value for war purposes. Galileo used the telescope to reveal the wonders of the heavens. He died in 1642, the year of the birth of Newton, exemplar of another method of scientific diseovery, "travelling through strange seas of Thought, alone". Newton invented the reflecting telescope, the prototype of which is still in the proud possession. of the Royal Society. The last-under construction in Californiawill in due course reveal new heavenly wonders, With apologies to Aristophanes, we may suggest that the frogs of Galvani are the most famous in the world. They hanged by a copper hook from an iron balcony. Galvani noticed that the dead frogs twitched when the wind brought their bodies into contact with the balcony. Thus the galvanic current was discovered, followed by the Voltaic pile, forerunner of the storage battery. Sir Richard Gregory in his book "Discovery" recalls that the Danish professor, Oersted, discovered induced currents by chance during a lecture experiment in 1819. Ampère, the French physicist, suggested that induced currents could be used for signalling at a distance, and two German men of science, Gauss and Weber, invented the first magneto-electric telegraph in 1833, a happy example of international co-operation in science. During Morse's experiments on telegraphy, a mile length of wire alongside a canal broke accidentally. Why not use the water of the canal ? Röntgen and Becquerel were favoured by chance in their important researches.

Iodine was accidentally discovered in 1811 by Courtois in the mother liquor of kelp. In those preMendeléeff days, no chemist would deliberately set about its discovery. Colonel Silver records that ebonite was discovered by the accidental over. vulcanization of a rubber ball. The hypnotic property of sulphonal was discovered by chance. Antipyrine, an invaluable drug, was in a sense a chance discovery. The cyanide industry, of great value to Germany, resulted from the accidental discovery of Prussian blue by Diesbach early in the eighteenth century. That most useful gas, acetylene, was discovered by accident. The American, Willson, and the Frenchman, Moissan, re-discovered calcium carbide in 1892 , working independently. Willson heated a mixture of coke and lime in an electric furnace in the hope of obtaining calcium. The resulting grey fusible mass was allowed to fall into a bucket of water and a copious supply of acetylene was produced. Chemists know of the result of a broken thermometer in relation to the oxidation of naphthalene and the synthetic indigo industry. Electro-plating benefited through a workman throwing his comrade's lump of cheese into a vat!

"Webster" defines chance as a supposed material or psychical agent or mode of activity other than force, law, or purpose. Force is as mysterious as space or time; law in its scientific sense a somewhat flyblown idol; purpose in its teleological sense a vague aspiration. Chanee relates to statistics, that queen of sciences, sadly contemned during the present War. We daily see provision made at great expense for war contingencies without regard to the principles of statistics and insurance. Nevertheless, physical science teaches that the most improbable events may happen. Stunned and stupefied by the wonders of modern science, the humble disciple is almost forced to the apostasy-Credo quia impossibile est. Was Newton a freak of Nature, due to some capricious combination of genes? Will the world be reduced to chaos by fortuitous collisions of electrons thrown out of their orbits?

Let us light a candle to the goddess of chance for boons received, for perils avoided !

Chance of chances, all is chance, says the Preacher. In a milligram of radium, about 500 million atoms disintegrate every second, each giving its characteristic radiation. How are these selected for destruction? Not by seniority nor by lot like shipwrecked mariners on a raft, says Sir James Jeans in his new book, "Physics and Philosophy". Are we offered an escape from determinism, from "the forbidding materialism of the Victorian scientist"? In the substratum below space and time, Jeans suggests, there may be springs of events including our own mental activities. The world made safe by democracy! Chance may be "the unsearchable dispose of highest wisdom". Quien sabe?

\section{OBITUARIES}

\section{Dr. F. S. Sinnatt, C.B., M.B.E., F.R.S}

The death of Dr. Frank Sturdy Sinnatt on January 27 at the comparatively early age of sixty-two has removed from the ranks of technical science one of its important figures. He was director of fuel research to the Department of Scientific and Industrial $\mathrm{Re}$ search, succeeding Prof. C. H. Lander in 1931.

Born in Jersey in 1880, Sinnatt was educated in Manchester, graduating M.Sc.(Tech.) in chemistry from the College of Technology in 1901. He obtained his D.Sc. at Manchester in 1930 and was elected a fellow of the Royal Society in 1935.

Originally a lecturer in organic chemistry under Sir William Pope, Sinnatt became interested in coal at an early stage in his career, and from personal research extended his work on the subject by organizing lectures in fuel technology and interesting university students in this relatively new branch of science. Coal technology fascinated him and soon absorbed his entire scientific interest. His researches and lectures attracted the attention of the local coal owners, and in 1918 he organized with them the Lancashire and Cheshire Coal Research Association and eventually became its first director. In 1924 he was appointed by the Department of Scientific and Industrial Research as assistant director of fuel research and as superintendent of the Fuel Research Coal Survey. In 1931 he succeeded Lander as director.

Sinnatt's published papers go back so far as 1906 . Two early researches (1923), which are still of academic and technical interest, are the carbonization of coal in the form of fine particles for the production of cenospheres, and the mechanism of the combustion of coal in the form of fine powder. In addition, his method for representing the structure of coal in coal seams is still in use. His papers on the examination of coal in the ground represent the first organized series to appear in Great Britain. His later publications are based mainly upon the work of the Fuel Research Station and the Fuel Research Coal Survey.

Sinnatt was thus not only one of the pioneers of survey work in coalfields, but also it is mainly due to his efforts that the National Survey of Coal Resources in Great Britain is so far in advance of coal surveys started in other countries. The records of the Survey have proved invaluable in war-time in defining the 